\title{
Evaluation of the potential for fractured unconventional reservoirs: A case study in the Candeias Formation, Socorro Field, Recôncavo Basin.
}

\author{
Lorena Gonçalves Dias André; Antonio Fernando Menezes Freire; Thaís Cândido da Silva; Thaís Alves de Oliveira; Wagner \\ Moreira Lupinacci.
}

Universidade Federal Fluminense

Copyright 2019, SBGf - Sociedade Brasileira de Geofísica

This paper was prepared for presentation during the $16^{\text {th }}$ International Congress of the Brazilian Geophysical Society held in Rio de Janeiro, Brazil, 19-22 August 2019.

Contents of this paper were reviewed by the Technical Committee of the $16^{\text {th }}$ International Congress of the Brazilian Geophysical Society and do not necessarily represent any position of the SBGf, its officers or members. Electronic reproduction or storage of any part of this paper for commercial purposes without the written consent of the Brazilian Geophysical Society is prohibited.

\section{Abstract}

A major limitation of the study of source rocks is the lack of geochemical data due to the small number of samples collected. Most of the time, sidewall core are only sampled in reservoir intervals, leaving a gap of information extracted directly from the rock outside these ranges. Well logs are an important tool to compensate for limitations with the absence of direct methods. In this work two indirect methods are applied in an attempt to evaluate a possible interval of fractured shale oil using well logs. The shales of the Gomo Member, of the Candeias Field, are known as a fractured reservoir, and is located just a few kilometers to the west of the Socorro Field, where there is an interval with high total organic carbon (TOC) content (> 4\%), high brittleness, lateral continuity and shallow depths, which was never evaluated as a complex unconventional reservoir. Based on gamma ray (GR), resistivity (RES) and sonic (DT) logs, calibrated with laboratory data, we applied the TOC $(\Delta \log R)$ and the free hydrocarbon content (S1s), the result of the application of the methods was combined to calculate the Oil Saturation Index (OSI). From the OSI it was possible to estimate a possible interval for a fractured hybrid shale oil.

Keywords: Petrophysics, Non-Conventional Resources, Fractured Reservoirs, TOC.

\section{Introduction}

In the exploration of hydrocarbons, the information about the source rock are of great importance, since the generation of oil or gas is directly related to the carbon content of this rock (JARVIE, 1991). However, studies of the quantity, type and maturation of the organic matter present are often neglected due to the lack of samples, since most of the wells only reach the depths of the reservoirs, not drilling the interval of the source rock, which is normally located in the deepest portion.

In this work, two methods were used to estimate the Oil Saturation Index (OSI), thus compensating the lack of rock data. For this, the gamma ray, resistivity and sonic logs calibrated with laboratory data were used in order to determine the efficiency of these methods.

This study was carried out in the Candeias Formation (Fm.), Socorro Field, Basin Recôncavo. This basin is located in the continental portion of the State of Bahia, and occupies an area of approximately $11,500 \mathrm{~km}^{2}$. Its boundaries are represented by the Aporá High to the north and northwest, by the fault system of Barra to the south, by the Fault of Maragogipe to the west and by the fault system of Salvador to the east (Fig. 1).

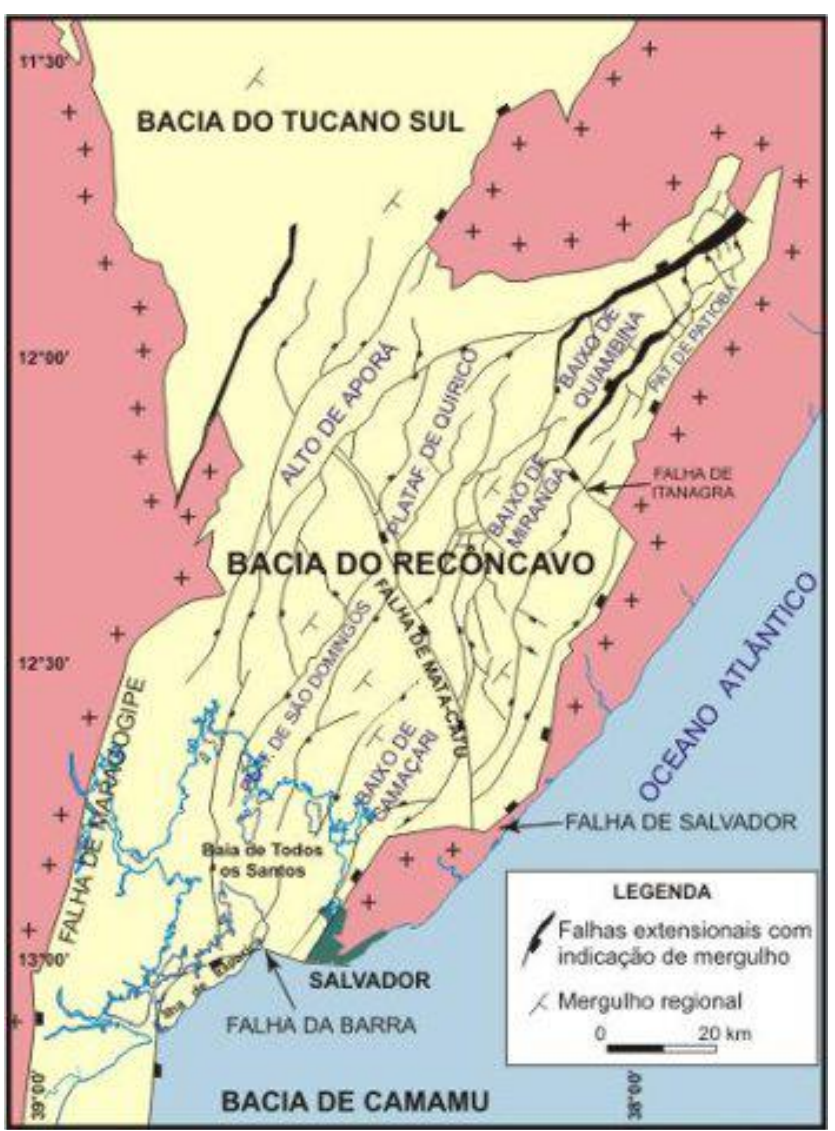

Figure 1: Location and Limits of the Recôncavo Basin. (Source: Milhomem et al., 2003).

According to Destro et al. (2003), the Recôncavo Basin is considered as a Rift type, where the entire RecôncavoTucano-Jatobá system was interpreted as an aborted portion. The tectonic evolution of this rift is related to the crustal stretch resulting from the fragmentation of the 
supercontinent Gondwana and the opening of the Atlantic Ocean. The tensions responsible for the rupture of the crust were supposedly active between the Middle Jurassic and the Upper Cretaceous (SILVA et al., 2007).

The basin can be divided into three stratigraphic supersequences: Pre-Rift, Sin-Rift and Post-Rift (SILVA et al., 2007). At the base of the Rift sequence, the Candeias $\mathrm{Fm}$. reflects the lacustrine context that prevailed at the beginning of this phase. The tectonic activity at this moment is intensified and shales, mudstones and turbiditic sandstones of the Gomo Member (Mb.) were deposited.

The Candeias Fm. is characterized by a predominantly clayey section, which is divided into two members: Gomo and Tauá. In the Tauá Mb., located at the base, predominate dark and fissile shales, while in the Gomo Mb. occurs greenish gray, laminated shales with thin layers of limestone and light gray fine sandstones (DALCERE, 2012).

Shales of the Candeias Fm. have great potential to be explored as a naturally fractured reservoir, following the example of Candeias Field, east of Socorro Field, the target area of this study. In Socorro Field, these fractured shales could be trapped by the extremely argillaceous sandstones of the Pitanga Mb., which makes this potential accumulation quite unique. The high productivity in the fractures of the Candeias Field encourages more researches in the region, being the main motivation of this work.

Fractures are associated with the normal and listric Neocomian faults (DAL-CERE, 2012). The fractured shales of the Candeias Formation occur mainly in the Gomo Mb. This interval in the Socorro Field (Fig. 2) by a strong resistivity growth, an increase in transit time, combined with high total organic carbon (TOC) values, which makes it a very interesting target for exploration.

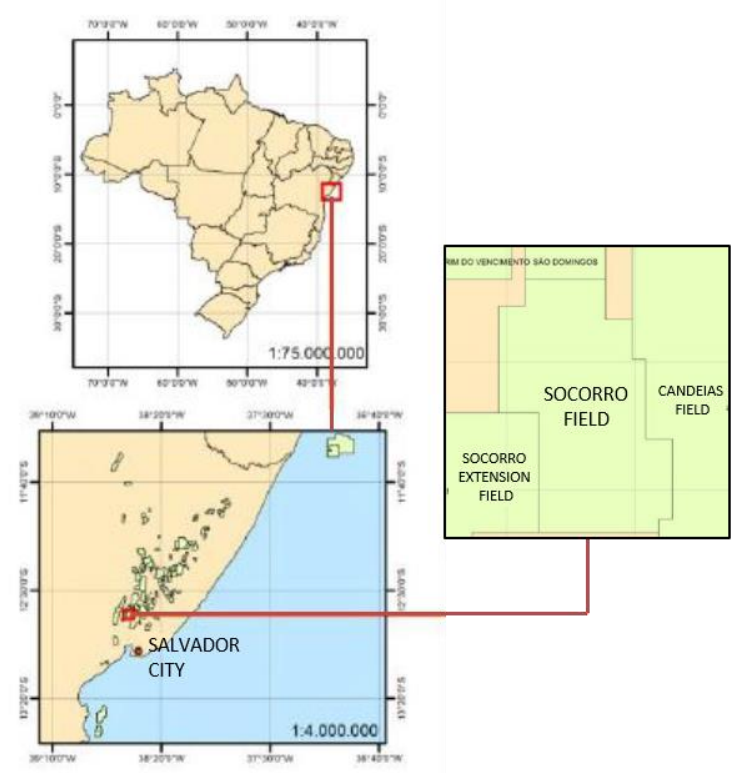

Figure 2: Localization map of the Socorro Field. (Source: ANP).

\section{Method}

The methodology of this work consists of the application of $\triangle \log$ R (PASSEY et al., 1990) and Synthetic S1 methods in geophysical well logs for the calculation of OSI (Oil saturation Index - JARVIE el al., 2012) and subsequent evaluation of a potential non-conventional reservoir.

$\triangle \log R$

The Passey method (Passey et al., 1990) was developed and tested by Exxon in 1979 and has been applied to several wells worldwide. This method assumes that rocks are composed of three components: matrix, solid organic matter and fluids that fill the pores. The method is based on the fact that source rock has different responses in logs, and proportional to the rock maturation. So, the curve changes are related to the solid organic matter that turns into fluid.

For the application of the method, the resistivity (RES) and sonic logs are required. The sonic log must be adjusted in the $-100 \mu \mathrm{s} /$ foot scale for every two logarithmic cycles of resistivity. After that, a baseline is defined in a non-source fine granulometry rock, where the resistivity and sonic curves are overlapped (Fig. 3). Then, the separation of the sonic and the resistivity curves in source rock intervals is called $\triangle$ LogR, which is linearly related to TOC depending on the maturity (PASSEY et al., 1990). The $\Delta \log R$ is calculated according to the equation 1 :

$$
\Delta \log R=\log _{10}\left(\frac{R}{R_{\text {bass }}}\right)+0.02 \times\left(\Delta T-\Delta T_{\text {base }}\right)
$$

where $R$ is the measured resistivity (ohm.m), $\Delta T$ is the measured transit time ( $\mu \mathrm{s} / \mathrm{m}$ ), and $R_{\text {base }}$ and $\Delta T_{\text {base }}$ are the resistivity and the transit time corresponding to the baseline, respectively.

The TOC can be calculated from the $\triangle \log R$ by the equation 2(PASSEY et al., 1990):

$$
T O C=(\triangle \log R) \times 10^{2.297-1688 \times \operatorname{LOM}}
$$

where TOC is the total organic carbon (wt \%) and $L O M$ is the level of maturity (Level of Organic Metamorphism), which was defined by Hood et al. (1975) as a linear scale of maturation, and can be used to estimate for organic matter present in sedimentary rocks of fine granulometry. LOM can be calculated from information such as Vitrinite Reflectance (Ro\%) and the maximum pyrolysis temperature (Tmax), reached at the peak of the generation potential (S2), or estimated from the burial rate (PASSEY et al., 1990).

A great advantage of this method is that even with an incorrectly estimated LOM, the relative values are still correct (PASSEY et al., 1990). In this work the method 
was applied after implementation in Python by Santos et al. (2017).

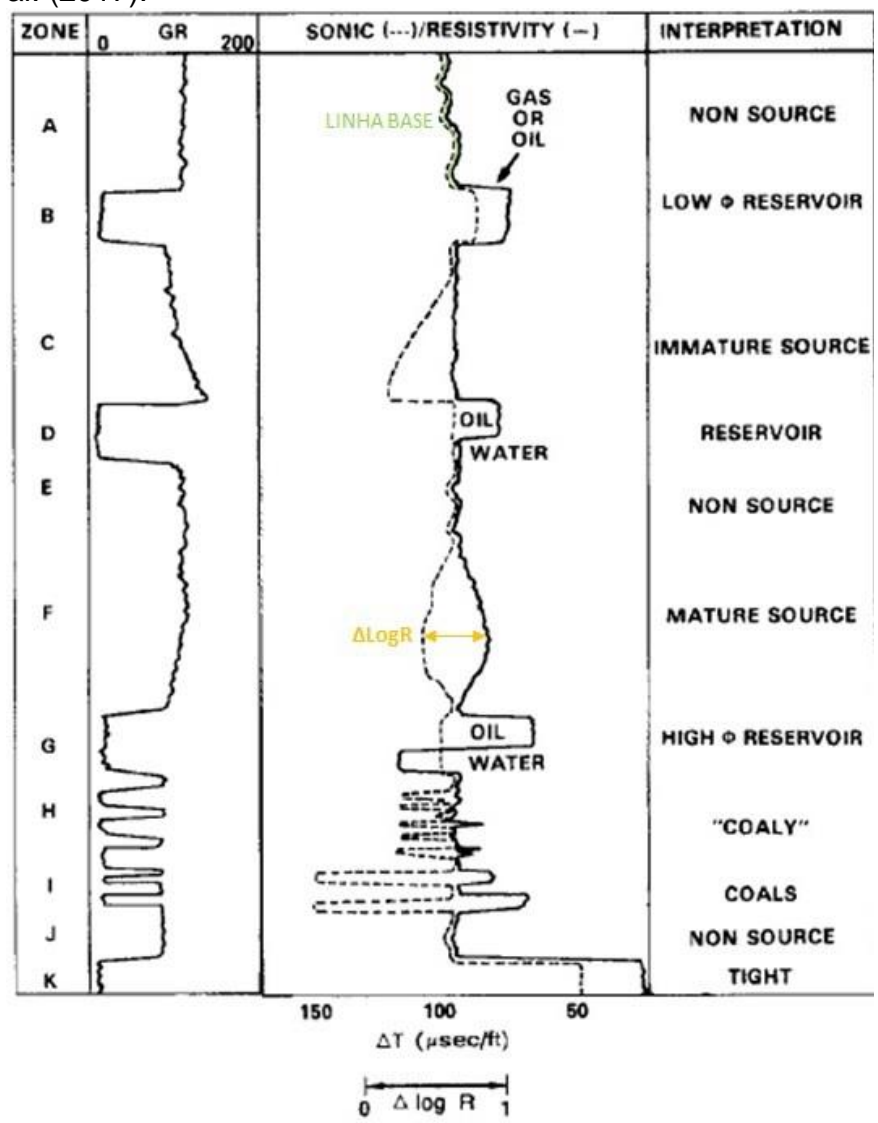

Figure 3: Scheme used to demonstrate the application of the method. In green the non-source interval used as baseline, in yellow the separation between the curves of the sonic $(\Delta T)$ and the resistivity (RES): the $\triangle$ LogR in that interval. (Modified from Passey et al., 1990).

\section{Synthetic S1 (S1s)}

Hélio Sérgio Rocha Lima e Silva (personal communication) developed an algorithm for the estimation of free hydrocarbons (S1), in an interval from gamma ray (GR) and resistivity (RES) logs. The method is based on the existence of a proportional relation between the values of a synthetic S1 (S1s) and the values of GR and an inversely proportional relation of the values of S1s with the values of RES. The author concluded that the S1s method is of great relevance for the calculation of areas, thicknesses and volumes of potential unconventional shale oil reservoirs.

In this work, the method was applied after its implementation in Python language. Details on the formulation of the algorithm for the calculation of the S1s should be consulted in the expanded abstract of Luza et al. (2019), also presented at this congress, where the full script is available.

\section{Oil saturation Index (OSI)}

Jarvie (2012) presents an evaluation of potential nonconventional shale oil reservoirs based on the calculation of the Oil Saturation Index (OSI).

The OSI is given by the use of $\mathrm{S} 1$ and analytical TOC values in the following equation(3):

$$
O S I=\frac{(S 1 \times 100)}{T O C}
$$

According to Jarvie (2012), when OSI values approach $100 \mathrm{mg} \mathrm{HC} / \mathrm{g} \mathrm{TOC}$, often considering the use of the minimum value of $80 \mathrm{mg} \mathrm{HC} / \mathrm{g} \mathrm{TOC}$, it is possible to infer a potential unconventional shale oil interval. Yet according to this author, the TOC and S1 quantities alone are not of sufficient relevance to determine the potential of a shale oil, as for example in the case of coal, which has values of about $10 \mathrm{mg} \mathrm{HC} / \mathrm{g}$ of rock and TOC of $50 \%$ or more, which makes the OSI very low indicating the impracticability of the oil exploration in this case.

The Gomo Mb. of the Candeias Fm. was chosen because it is a naturally fractured shale, with intercalations of mudstones with high TOC content. These factors make this interval a good candidate for the application of the methods described above.

The Well 3SC 0017 BA was chosen for the calibration and the application of these methods, since it counts on geochemical data that are of great importance in the calibration and the comparison of the results. Figure 4 highlights this interval, where the of GR, RES and $\Delta T$ increase values.

\section{Results and Discussion}

\section{Application of the $\Delta \mathrm{LogR}$ and the S1s methods}

From the application of the tools in Python language implemented by researchers of the Fluminense Federal University, the TOC and S1s responses were generated in the interest interval.

During the application of the methods, it was possible to observe a delay in the return of the samples by the vertical difference of the curve calculated with the samples measured in the laboratory in the range of 900 to 980 meters (Fig. 5).

For the application of the $\Delta \log R$ method, the baseline definition was made in a very singular way. In this study the baseline was defined on the sandstone of the Pitanga $\mathrm{Mb}$., which is a very clayey sandstone with very low permeability in the range of 700 to $900 \mathrm{~m}$ (Fig. 5). It is a very impermeable sandstone $(<0,01 \mathrm{mD})$, of very fine granulometry, that works as trap rock of this unconventional reservoir. 


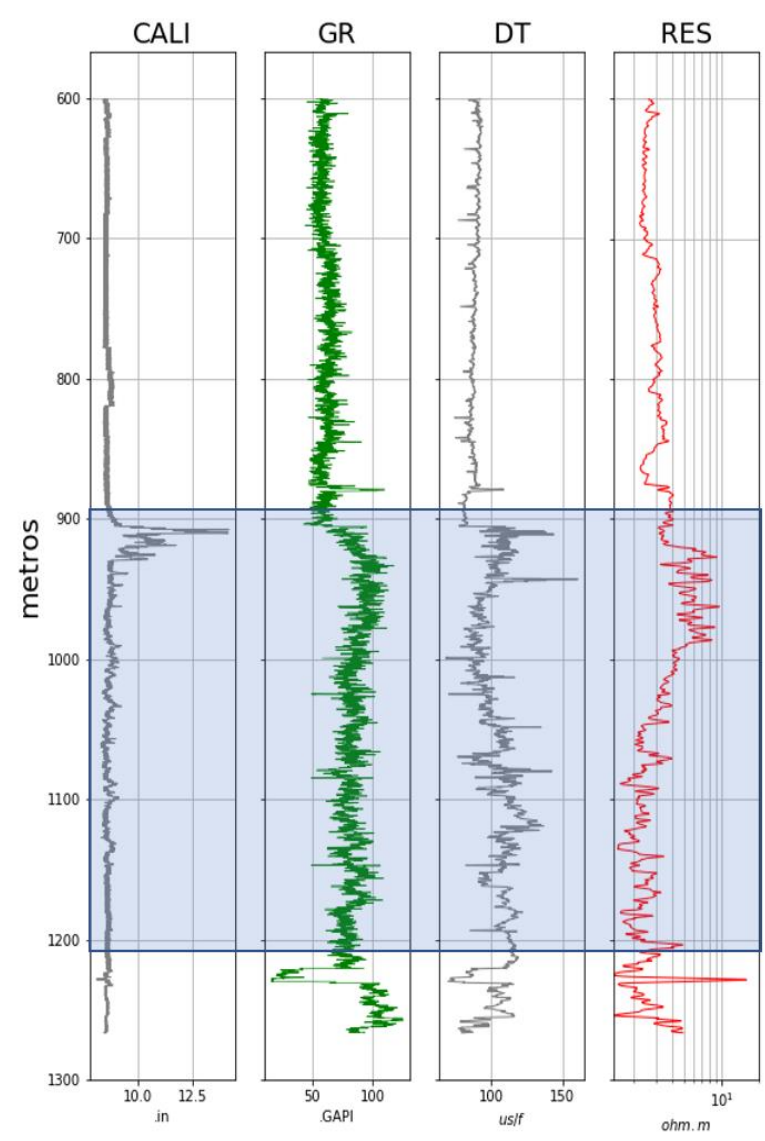

Figure 4: From left to right: caliper (CAL), gamma ray (GR), sonic (DT) and Resistivity (RES) curves are shown. The interval of study chosen for the evaluation of potential shale oil.is highlighted. Notice the high caliper values at the top of the interval of interest, disrupting interpretation in that portion.

\section{OSI Calculation}

The S1s and the $\Delta$ LogR curves generated were used to calculate the OSI. The TOC curve given by the $\triangle$ LogR method was smoothed in order to alleviate the disparities of values generated from caving problems, showed by the caliper log in the upper range of the interval of interest (Fig. 4). After this smoothing, the curves were plotted and the OSI calculation applied to them.

It is clear the presence of outliers when plotting the curves according to Figure 6 . The two points were removed and a new curve was generated and a better fit was obtained (Fig. 6).

In the OSI charts, the blue line indicates the cutoff, where the values are greater than $80 \mathrm{mg} \mathrm{HC/g} \mathrm{TOC}$, and according to it the interval inferred as a potential unconventional shale oil and is also highlighted in blue in Figure 6. However, Tmax values approach $445^{\circ} \mathrm{C}$ and suggest that the interval is at the beginning of the oil generation window, indicating that the possible accumulation is the result of a migration through faults. In this case, the potential unconventional reservoir could be considered a fractured hybrid shale oil.

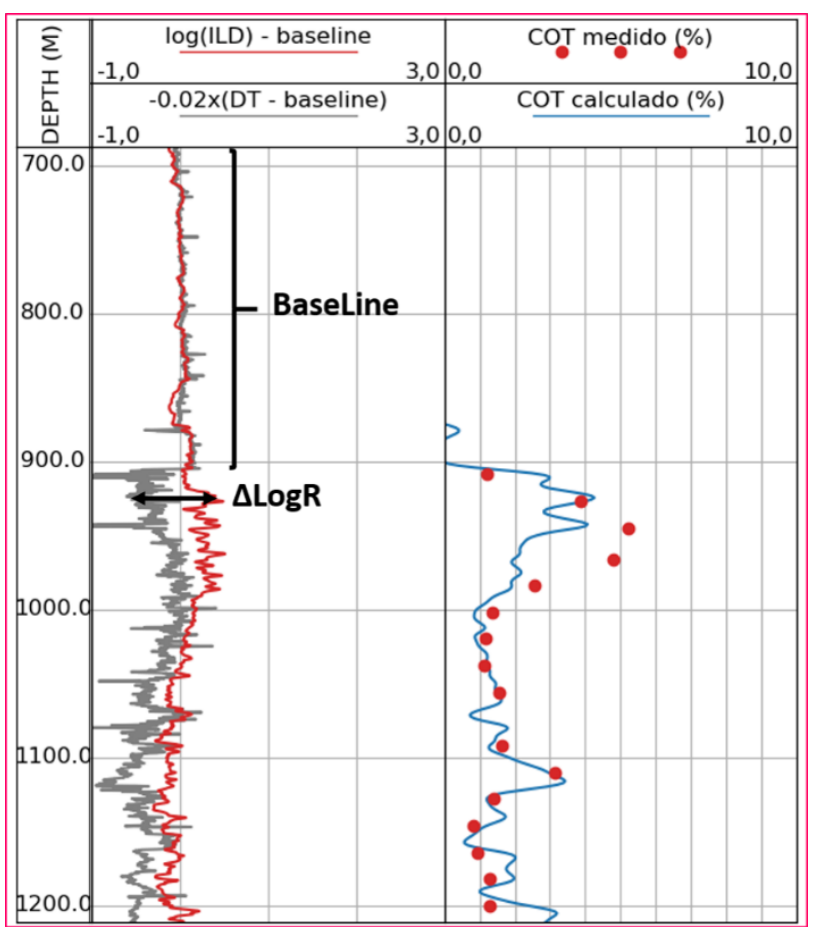

Figure 5: Application of $\Delta \mathrm{LogR}$ in Well 3SC $0017 \mathrm{BA}$. In the first track in red the RES curve and in gray the $\Delta T$ curve. The distance between the curves is called $\Delta$ LogR. In the second track in red the TOC points measured in laboratory and in blue the TOC curve estimated by the $\Delta$ logR method.

The work is in progress and will continue in other wells in the same field to a better understanding of the unconventional reservoir present there.

\section{Conclusions}

The use of well logs for the approximate calculation of geochemical parameters is efficient and valid, since not all wells have analytical geochemical data. On the other hand, the presence of basic well logs, such as GR, RES and $\mathrm{DT}$, in most of the wells allows the extrapolation of TOC and S1 geochemical parameters throughout the field and even used in a regional basin scale. Further calibrations should be performed to validate the methodologies used, since there are several variables involved in the calculations. In the specific case of the Socorro Field, the caliper problem observed at the top of the interval of interest complicate a correct evaluation of the analyzed methods. 
With Outliers

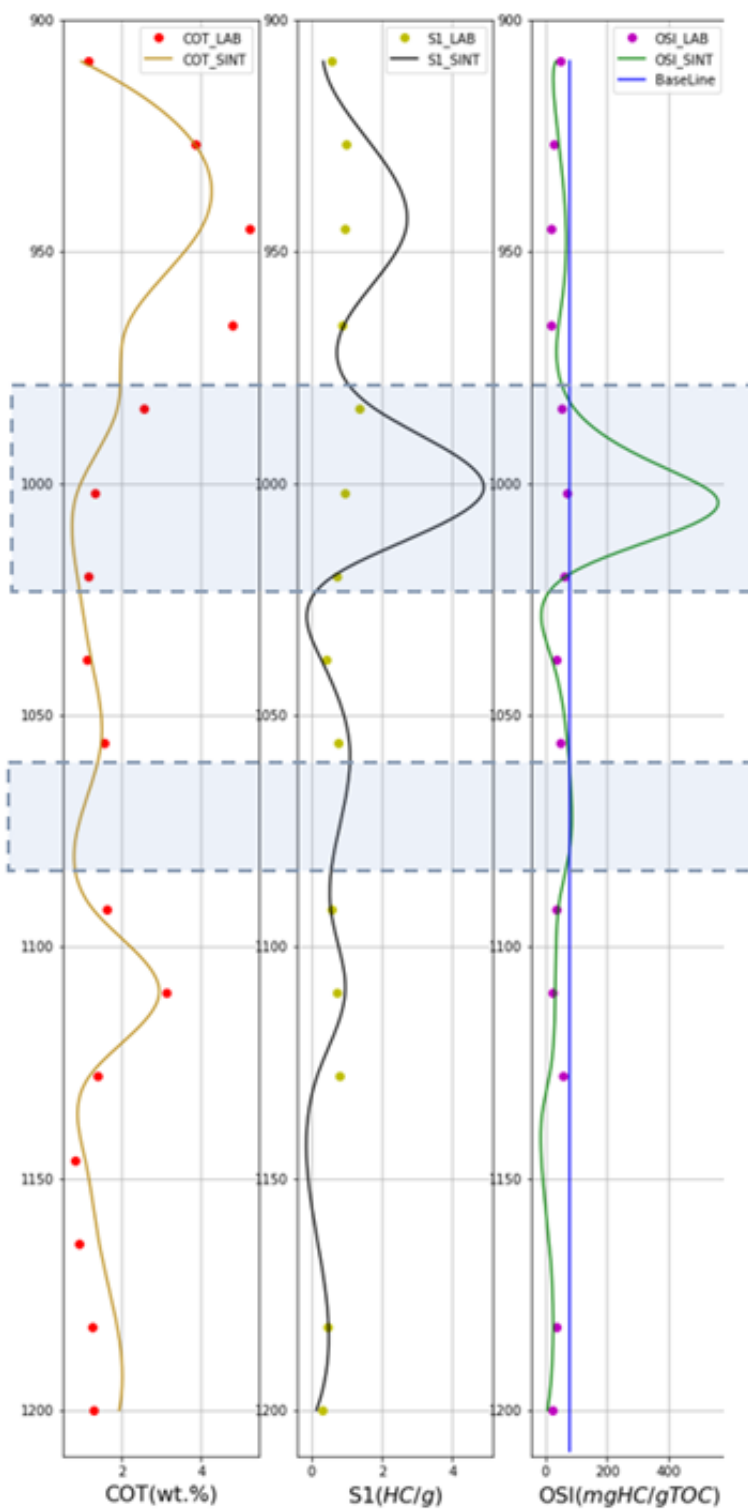

Outliers removed

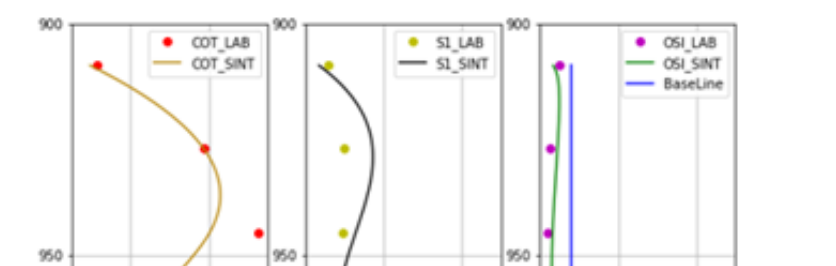




\section{References}

DAL-CERE, P. R. Reservatório de gás não convencional: história de caso na Bacia do Recôncavo - Brasil. 2012.

Hood A., Gutjahr C. C. M., Heacock R. L.. Organic Metamorphism and the generation of Petroleum' The origin of petroleum can be described generally by four successive stages: (1) the formation of organic-rich, finegrained sediments through the photosynthesis, deposition, and preservation. AAPG Bulletin, v. 6, n. 6, p. 986-995, 1975.

JARVIE, D.M. (2012). Shale Resource Systems for Oil and gas: Part 2 - Shale-oil resource Systems. in J.A. Breyer, ed., Shale Reservoirs - Giant resources for the $21^{\text {st }}$ century: AAPG Memoir 97, p. 89-119.

JARVIE, D. M. Total organic carbon (TOC) analysis: Source and migration processes and evaluation techniques. In: Source and Migration Processes and Evaluation Techniques. Texas: AAPG, 1991. cap. 11, p. 113-118.

Edson Alonso Falla Luza, Maria Luiza Cyrino Paiva, Hélio Sérgio Rocha Lima e Silva, Antonio Fernando Menezes Freire (Presented at this congress) - Development of an algorithm to infer the free hydrocarbon content(S1) from well logs.

Milhomem P.,Maman E., Oliveira F., Carvalho M. SouzaLima W.Bacia do Recôncavo. Fundação Paleontológica Phoenix, v. 51, 2003.

Passey Q. R., Creaney S., Kulla J. B., Moretti F. J., Stroud J. D. Practical model for organic richness from porosity and resistivity logs. 1990. 1777-1794 p.

F. V., Freire A. F. M., Lupinacci W. M.. Aplicação da técnica delta log $\mathbf{R}$ para estimativa de carbono orgânico total (COT) utilizando perfis de poços da Bacia de Campos.

Silva O., Caixeta J., Milhomem P., Kosin M.. Bacia do Recôncavo. Rio de Janeiro: Boletim de Geociências da Petrobras, 2007. 423-431 p. 